\title{
Task Experiential Teaching Method and Its Application in Ship Structure and Equipment Course
}

\author{
Lijun Wang, Sisi Wang* \\ Navigation School, Guangdong Ocean University, Zhanjiang, 524088, China \\ *Corresponding author: wangss@gdou.edu.cn
}

Keywords: Ship structure and equipment; task drive; experiential teaching; education

\begin{abstract}
This paper discusses the application of task experiential teaching mode in ship structure and equipment course. Firstly, the characteristics, structure and process of task experiential teaching mode are studied in detail. Then based on the characteristics of ship structure and equipment course and navigation education resources in Guangdong Ocean University, the specific task experience teaching mode is discussed and the feasibility analysis is carried out. It is concluded that task experience type teaching mode can make full use of various teaching resources, and the teacher's role is transformed into a teaching organizer. With the students as the center of the task experience teaching, the theory teaching is connected with the practice training, which can greatly improve students' learning initiative and navigation application skills in accordance with STCW. In a word, classroom teaching is not consistent with navigation practice, and task experience type teaching mode is of great significance for the expansion of navigation education.
\end{abstract}

\section{Introduction}

Ship structure and equipment (SSE) is one of the major specialized courses of marine technology, and also a national unified examination course for the certificate of competency (CoC). The teaching of this course is to make students have the basic principle and common sense of ship hull structure and equipment, operate properly, use and maintain the deck equipment to meet the requirements of the modern shipping industry. As a professional basic course, the teaching requirements include the perceptual knowledge of SSE, shipbuilding engineering aspects of the rational, and navigation skills application capacity. Therefore, it is difficult to achieve the ideal teaching effect by only theory teaching. In accordance with the perceptual knowledge of the ship and its structural equipment, one divides the stages of classroom teaching in a reasonable manner, including the theory of task-based and its interpretation, learning and difficult problems to collect method. Finally, summarize the theory combined with the actual learning and sharing ${ }^{[1-3]}$.

Firstly, the classroom dimension is expanded, the theoretical explanation is condensed into specific learning tasks, and the teacher's role has changed to become a learning task organizer. Secondly, the classroom is no longer confined to the classroom, the class will be moved to a certain ship, to make the learning process no longer a passive acceptance and dull rote learning, but a kind of immersion experience; finally, theoretical study and practical learning are integrated and analyzed, then personal summary and group discussion are conducted. This course will end in the sharing of knowledge so as to realize the change of teaching effect from knowledge infusion to ability. Therefore, it is necessary and effective to carry out experiential reform of SSE course teaching.

The foreign experiential teaching thought can be traced back to the teaching thought of ancient Greece, Comenius, Rousseau naturalism and Dewey empiricism. However, although the abroad experience teaching ideology has a long history, the experience type teaching (ETT) research are very few, the researchers focus attention on the study of experiential learning, especially the study on the model of experiential learning, this may be related to foreign education research emphasis has shifted from teaching methods to learners ${ }^{[4-8]}$.

There are relatively many researches on ETT in China, but it is also in the early stage. Pedagogy, foreign language teaching, the study of ETT still stay in the ETT characteristics, value and its realization ways, only a few researchers begin to pay close attention to the establishment of the ETT mode. The core 
of ETT is "task". The quality of learning tasks assigned by teachers is very important. The task of the proper difficulty, the exploration significance and the guidance of the division of labor are to guide the students to realize the important driving of the active exploration. As a result, the ETT effect is discounted without the appropriate task drive.

The so-called "task drive" is to guide students to produce a kind of learning practice tightly focusing on a common task activity, under the drive of strong problem motivation, through the active application of learning resources. "Task-driven" is a kind of teaching method based on constructivism teaching theory, which requires the objective of "task" and the creation of teaching context ${ }^{[9-10]}$. Therefore, high-quality learning tasks and ETT are complementary. The core of this kind of teaching method is the students, just as shown in Fig 1.

\section{Theoretical Basis and Research Status}

ETT refers to the presentation or reproduction of the teaching content based on the students' cognitive characteristics and rules and the creation of actual or repeated experiences. It enables students to understand and construct knowledge, develop the ability, generate emotion and generate meaning in the process of personal experience. ETT is based on the development of human life, respect for life, and care for life, extend life and improve life, and contain high life value and meaning. What it cares about is not only how much knowledge and what knowledge people can acquire through teaching, but also the significance of human life.

The task experiential teaching mode (TETM) creates a form of interaction between teachers and students and emphasizes the bilateral emotional experience of teachers and students. Teaching process is not only the information communication between teachers and students, as well as emotional communication between teachers and students, the ETT should be carried out under an atmosphere of harmony is smooth, so the teachers' ability of the organization and emotional coordination level put forward certain requirements.

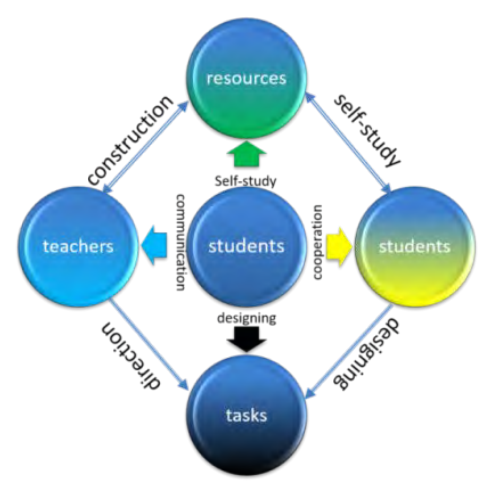

Fig. 1 Module of the TETM

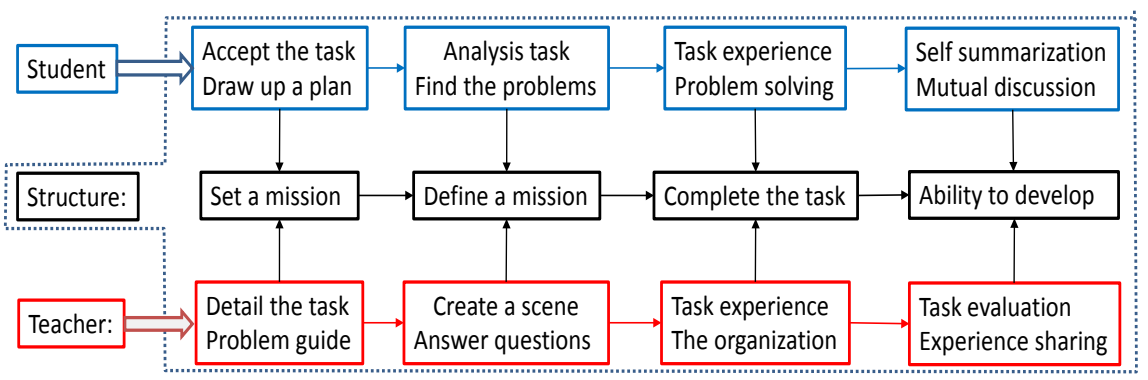

Fig. 2 The flow chart of the TETM

TETM is a kind of teaching method based on constructivism learning theory, which transforms the traditional teaching concept, which is based on the teaching of knowledge, into the multi-dimensional interactive teaching concept that focuses on solving problems and completing tasks. Students' learning activities must be combined with tasks or problems to explore problems to guide and sustain learners' interest and motivation. Creating a real teaching environment so that students can study with real tasks, so that students have the initiative and the desire to learn. Students' learning is not only the transfer of knowledge from the outside to the inside but also the process of students' initiative to construct their own knowledge experience. Through the interaction between the new experience and the original knowledge experience, enrich and enrich their knowledge and ability. The specific processes and patterns are shown in Fig 2.

At the same time, navigation technology is a typical application technique. The learning process is the process of learning skills. It is difficult to master the necessary professional quality without personal experience and skill experience. SSE is the first specialized basic course, which has a strong connecting 
role. The study of perceptual knowledge is very important, and the maritime cognition practice in the same semester also provides favorable conditions for TETM.

The main theoretical basis is as follows: (1) The principle of interaction between emotional and cognitive activities. (2) Intuitive principles of cognition. (3) The similarity principle of thinking science. (4) The cognitive activity of is unity of conscious and unconscious mental activity. (5) The cognitive process is the unification of intelligence and non-intelligence factors.

The basic principles of teaching tasks are as follows. First, the principle of unity of consciousness and unconsciousness and the principle of unity of intelligence and non-intelligence. Secondly, the pleasure and relaxed experiential principle. Finally, the principle of autonomy of mutual trust and mutual trust between teachers and students.

The core of the TETM is how to stimulate and guide students' emotion properly, which can not only stimulate students' interest in courses but also help to cultivate their creative thinking.

From the perspective of students, task-driven is an effective learning method. It greatly improves the learning efficiency and interest, cultivate their independent exploration, have the courage to forge ahead of the self-study ability.

From the perspective of teachers, task-driven is the teaching method based on constructivist teaching theory. The traditional teaching concept will be transferred to solve the problem by the students themselves, just as shown in Fig.3. The general procedure is as follows.

(1) Create a situation and give assignments to students: enable students to learn in a situation that is basically consistent with or similar to the reality.

(2) Determine the problem (task) by them: In the context of creation, choose the authenticity event or problem (task) that is closely related to the current learning topic as the center of learning.

(3) Autonomous learning and collaborative discussion: Instead of telling students directly how to solve the problem, teachers should provide students with clues to solve the problem.

(4) Effect evaluation: The evaluation of the learning effect mainly consists of two parts. On the one hand is the evaluation of the process and outcome of the solution. The more important aspect is the evaluation of students' autonomous learning and cooperative learning ability.

\section{Research Significance}

China's higher education has always been a problem that attaches great importance to theory and ignores practice. The modern university system requires that education should pay attention to practice. The task experience teaching method provides a practical idea for the education mode of combining theory with practice. It also puts forward some meaningful suggestions for Guangdong Ocean University (GDOU) in the cultivation of Marine technology applied talents.

SSE as the main course of Marine technology major, the teaching requirements include perceptual knowledge of SSE, professional rationality in shipbuilding engineering, and application ability of navigation skills. It is difficult to achieve the ideal teaching effect only by theoretical teaching. Therefore, it is very necessary to combine the perceptual knowledge of ships and their structural equipment in the understanding of maritime cognition. Divide classroom teaching into reasonable stages. It contains theoretical tasks and explanations, practical ship investigation, learning and problem collection, theory and practical learning summary and sharing. The benefits are as follows.

(1) Expand the classroom dimension and simplify the theoretical explanation to the specific learning task. The role of the teacher has changed, from the teacher to a learning task organizer. In particular, seafaring technical teachers must meet the requirement of double teacher qualification. At the same time, enthusiasm for teaching is the key to the success of the TETM.

(2) The teaching scene is as professional and realistic as possible, the classroom is no longer confined to the classroom, and the class will be moved to the ship to some extent, or make full use of the virtual simulation scenarios provided by equipment such as large ship maneuvering simulator. The maritime college of GDOU has a relatively advanced ship simulator and other navigational instruments and its simulation equipment. On the other hand, it has set up an internship base in several shipping companies. 
In a word, the university is doing best to provide the necessary conditions for the task experience teaching, just as shown in Fig.4.

(3) Theoretical study and practical learning are integrated and analyzed. According to the teaching experience of foreign universities, personal summary and group discussion are a necessary teaching link. End this course in the sharing of knowledge so as to realize the change of teaching effect from knowledge infusion to ability. With the development of society, compound talents are more important. The theoretical analysis ability and practical ability of college students cannot be deviated. TETM is a very meaningful exploration to perfect university education itself.

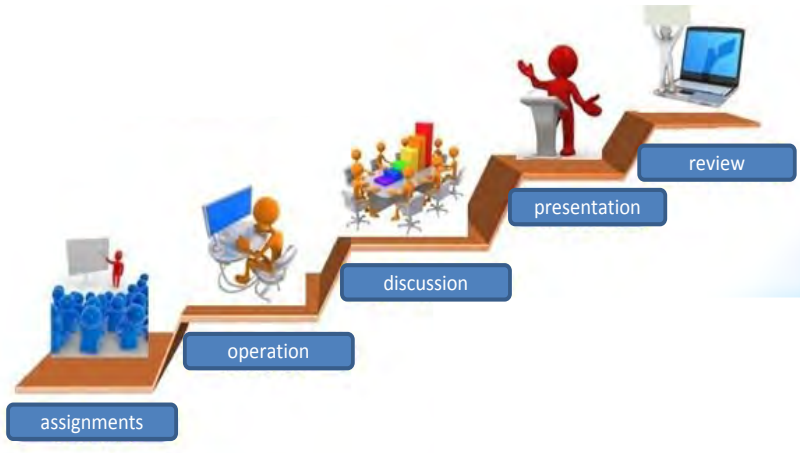

Fig. 3 The teaching steps of TETM

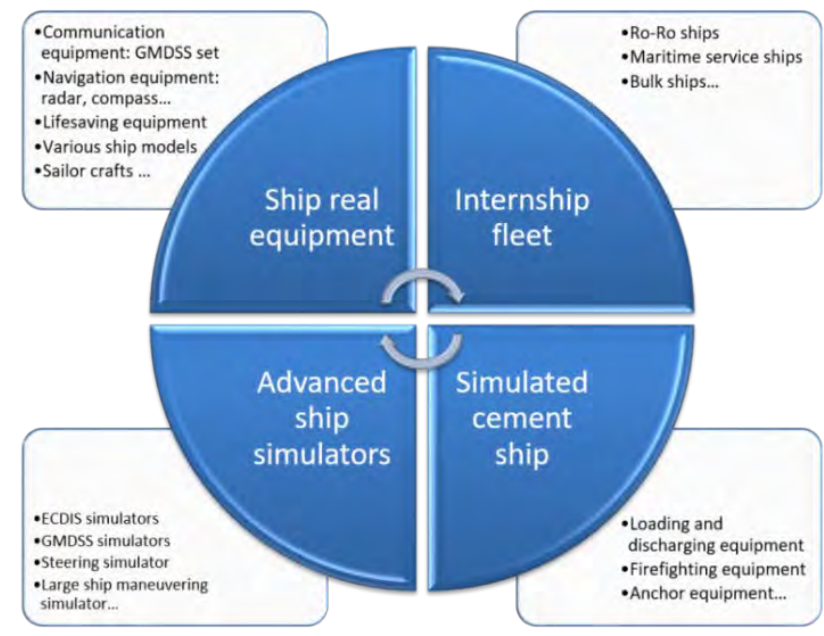

Fig. 4 Virtual teaching resources in GDOU

\section{Key Issues to be Resolved}

Current problems in SSE courses in GDOU:

- The students only learn the textbooks, and the knowledge update is not timely;

- The students' perceptual knowledge of ships is seriously inadequate;

- The student participation is limited, affected the learning initiative and the effect;

- Not combining with the maritime cognition practice,

- The examination method is single, without the ability formation and skills training.

To solve the above problems, we can carry out the following issues. Firstly, we should put forward the task decomposition method, learning task standard and teaching organization form of SSE course. Secondly, an experiential learning environment scheme to create immersive and immersive experience is necessary to be brought up, and then we should develop teaching organization procedures in the case of real ship and large ship maneuvering simulator. Thirdly, based on analyzing the key elements of the combination of theoretical study and practical learning. To formulate the teaching outline, teaching plan and experimental teaching plan of SSE course based on mission experiential teaching mode.

\section{Feasibility Analysis in GDOU}

The teaching team of SSE mostly have more than 10 years of professional teaching experience, familiar with the theoretical basis of SSE course and practice skills, and follow the related international conventions and national maritime safety administration of IMO regulations;

The teaching team members as navigation technology professional full-time teachers for many years, there are five teachers with senior crew certificate, there are three teachers with PH.D, maritime education experience, have a better understanding of the development of maritime education. In recent years, they have presided over a number of teaching reform projects, including 4 provincial-level education reform projects, and published more than 10 related academic papers.

In the establishment of ship class and virtual classroom, GDOU navigation school has a relatively complete marine education resource, just as shown in Fig.3. Firstly, the school has its own shipping 
company. Second, with Zhanjiang Shipping Group, Hainan strait joint-stock company and so on established the internship fleet; Thirdly, our institute has the V.Dragon 2000 large-scale ship control simulator and ECDIS simulation system, and its performance indicators fully meet the requirements of China's maritime department and STCW convention, which can be used to construct virtual classes. It is worth noting that the above equipment and resources are in continuous complete.

\section{Conclusion}

In this paper, one focuses on the application of TETM in SSE course. Firstly, the characteristics, structure and process of TETM are studied in detail. Then based on the characteristics of SSE course and Guangdong Ocean University navigation education resources, the specific task experience teaching mode is discussed and the feasibility analysis is carried out. Conclusion is task ETT mode, can make full use of various teaching resources, the teacher role is transformed into a teaching organizer. With the students as the center of the task experience teaching, the theory teaching is connected with the practice, which can greatly improve students' learning initiative and navigation application skills. In a word, classroom teaching is more consistent with navigation practice. This research is of great significance for the expansion of navigation education.

\section{Acknowledgement}

This work is partially supported by teaching reform projects of Guangdong Ocean University [No.524210274, 530002001165], scientific research start-up funds of Guangdong Ocean University [No.E15031, R17012], Characteristic Innovation Projects of Guangdong province Grants 2017KTSCX088, 2017KTSCX092; and college student innovation and entrepreneurship training program of Guangdong province [No. 530002001095], education reform project of the education department of Guangdong Province [525000049].

\section{References}

[1]. Douglas S R, Kim M. Task-based language teaching and English for academic purposes: An investigation into instructor perceptions and practice in the Canadian context [J]. TESL Canada Journal, 2015, 31: 1.

[2]. Rop G, van Wermeskerken M, de Nooijer J A, et al. Task experience as a boundary condition for the negative effects of irrelevant information on learning [J]. Educational Psychology Review, 2018, 30(1): 229-253.

[3]. Calvert M, Sheen Y. Task-based language learning and teaching: An action-research study [J]. Language Teaching Research, 2015, 19(2): 226-244.

[4]. Nespor J. The role of beliefs in the practice of teaching [J]. Journal of curriculum studies, 1987, 19(4): 317-328.

[5]. Nunan D. Task-based language teaching[M]. Ernst Klett Sprachen, 2006.

[6]. Alizadeh T, Tomerini D, Colbran S. Teaching planning studios: an online assessment task to enhance the first year experience[J]. Journal of Planning Education and Research, 2017, 37(2): 234-245.

[7]. Middleton M, Rheingold A, Seaman J. Activity Settings as Contexts for Motivation: Reframing Classroom Motivation as Dilemmas Within and Between Activities [M]. Constructivist Education in an Age of Accountability. Palgrave Macmillan, Cham, 2018: 231-266.

[8]. Park S. Analysis of Time-on-Task, Behaviour Experiences, and Performance in Two Online Courses with Different Authentic Learning Tasks [J]. The International Review of Research in Open and Distributed Learning, 2017, 18(2). 
[9]. Evans S, Myrick J G. How MOOC instructors view the pedagogy and purposes of massive open online courses[J]. Distance Education, 2015, 36(3): 295-311.

[10]. Rockoff J E. The impact of individual teachers on student achievement: Evidence from panel data [J]. American Economic Review, 2004, 94(2): 247-252. 